\title{
Awareness of cervical cancer and practice of Papanicolou smears among adult women availing health services or visiting a rural maternity hospital, Ramnagara District, Karnataka, India
}

\section{Chandralekha Kona, Merlyn Joseph, Jilshy Varghese, Mary Aksha, Anju Joseph, Ria Jose, Avita Rose Johnson*}

Department of Community Health, St. John's Medical College, Bangalore, Karnataka, India

Received: 22 August 2019

Accepted: 30 September 2019

\section{*Correspondence:}

Dr. Avita Rose Johnson,

E-mail: avita@johnson.in

Copyright: () the author(s), publisher and licensee Medip Academy. This is an open-access article distributed under the terms of the Creative Commons Attribution Non-Commercial License, which permits unrestricted non-commercial use, distribution, and reproduction in any medium, provided the original work is properly cited.

\begin{abstract}
Background: Cervical cancer is a leading cause of cancer-related deaths among women worldwide. Almost $87 \%$ of cervical cancer deaths occur in low and middle-income countries. The study was conducted to assess the awareness of cervical cancer and practice of Papanicolou (Pap) smears among women availing health services or visiting a rural maternity hospital, Karnataka.

Methods: A hospital-based cross-sectional study was conducted using a 50-item interview schedule. The interview was administered to women $>18$ years of age who availed services at the hospital and their caretakers.

Results: Mean age of the 158 women interviewed was $32.68 \pm 13.7$ years. Only $21 \%$ of women had heard about cervical cancer. Only $11.4 \%$ knew at least one symptom and $1.9 \%$ knew one risk factor of cervical cancer. Most of the women $(99 \%)$ were not aware about prevention of cervical cancer. Only $4 \%$ of the women had heard about Pap smears and $3 \%$ of the women had undergone a Pap smear test.

Conclusions: Women in our study had very poor awareness of cervical cancer and practice of Pap smears. Gainfully employed women $(\mathrm{OR}=32 ; 8.8-111.2)$ and women who reported cervical cancer among family members or friends $(\mathrm{OR}=116 ; 20.2-665.4)$. were more likely to have heard about cervical cancer. This study indicates a need to increase the awareness on cervical cancer and its prevention especially regarding Pap smears among rural women in Karnataka.
\end{abstract}

Keywords: Awareness, Cervical cancer, Cross-sectional study, Papanicolou smear, Practices

\section{INTRODUCTION}

Cervical cancer is easily preventable, but remains one of the most deadly cancers among women, with a global estimation of about 5,30,000 new cases and 2,75,000 deaths each year. ${ }^{1,2}$ Almost $87 \%$ of deaths due to cervical cancer occur in low and middle income countries. ${ }^{3}$ This is in contrast to developed countries where the cervical cancer mortality has declined due to Papanicolou (Pap) smear screening and introduction of Human papilloma virus (HPV) vaccine as a part of routine immunisation. ${ }^{4}$ HPV vaccination can decrease the burden of cervical cancer in the community by $75 \% .5$ Every year around 1 , 32,000 cases and 77,000 deaths from cervical cancer occur in India, and this burden is projected to increase to $2,00,000$ by the year $2025 .^{6}$

The incidence of cervical cancer rises at 30-34 years of age and peaks at 55-65 years. ${ }^{1}$ Regular screening with Pap smear of sexually active women decreases cervical 
cancer incidence and mortality by $80 \% .^{7}$ It is necessary to have adequate awareness about cervical cancer and its prevention, as this will help in its early detection, diagnosis and treatment thus reducing the disease burden. The National Program for prevention and control of cancers, diabetes, cardiovascular diseases and stroke (NPCDCS), lays emphasis on screening for cervical cancer for all women above 30 years of age. ${ }^{8}$ The success of this programme will first depend upon awareness of cervical cancer and the need for screening, as this would determine uptake of screening tests, and eventually follow-up, diagnosis and treatment of pre-cancerous and cancerous lesions detected. There is paucity of data regarding the awareness of rural South Indian women with regards to cervical cancer and Pap smears. This study aimed to determine the awareness of cervical cancer and practice of Pap smears among women availing health services or visiting a rural maternity hospital in South Karnataka and to determine associated factors. This study hopes to add to the body of knowledge regarding cervical cancer which would help to design targeted interventions within the existing cervical cancer strategies.

\section{METHODS}

This was a cross-sectional study, conducted at a rural maternity hospital in Ramnagara District, Karnataka over a two month period (July 2018 to August 2018).The sample size was calculated as 158 , taking $20 \%$ relative precision and $95 \%$ confidence limits, based on a previous study done in Andhra Pradesh where $37.3 \%$ women had adequate awareness about cervical cancer. ${ }^{9}$ Convenience sampling method was followed. All women above 18 years of age who availed the outpatient or inpatient health services as well as female caretakers and visitors were included in the study. All seriously ill patients and those who were unable to comprehend the questions (due to old age or mental health issues) were excluded from the study. Institutional Ethics Committee approval was obtained for this study and permission was taken from the in-charge of the rural maternity hospital. After explaining the purpose of the study, a written informed consent was taken from the participants, and the face-validated, pretested study tool was administered. This was a 50-item semi-structured interview schedule consisting of sociodemographic details, awareness of symptoms, risk factors, screening and treatment of cervical cancer, HPV vaccination and practice of Pap smears.

\section{Statistical analysis}

The data collected was entered in Microsoft Excel 2010 and analyzed using SPSS Version16. The data was described using frequencies, proportions, mean and standard deviation. Awareness of cervical cancer and practice of Pap smears were associated with various socio-demographic factors using tests of significance such as Chi square test and Fischer exact test as applicable. A p-value of $<0.05$ was considered significant. Significantly associated variables were entered into a multivariate logistic regression model.

\section{RESULTS}

A total of 158 women participated in this study. The mean age of the participants was $32.68 \pm 13.7$ years. Majority of the participants were married with mean age at marriage being $19.49 \pm 3.4$ years. The study subjects had a mean parity of $2.28 \pm 1.1$. Mean years of formal education among the subjects was $9.39 \pm 4.4$ years. Most of them were home-makers $(84 \%)$ and from a rural area (94\%). Majority were Hindu by religion and nearly threefourth had delivered more than once (Table 1). Mean years of education of the study subjects was $9.39 \pm 4.44$ years. $13.3 \%$ reported knowing someone suffering from cervical cancer among family and friends.

Table 1: Socio-demographic profile of the study participants $(n=158)$.

\begin{tabular}{|l|l|}
\hline Variables & $\mathbf{N}(\%)$ \\
\hline Age groups & \\
\hline$\leq 20$ years & $24(15.1)$ \\
\hline $21-30$ years & $69(43.7)$ \\
\hline 31-40 years & $26(16.5)$ \\
\hline$\geq 41$ years & $39(24.7)$ \\
\hline Religion & \\
\hline Hindu & $133(84.2)$ \\
\hline Muslim & $16(10.1)$ \\
\hline Christian & $9(5.7)$ \\
\hline Parity & \\
\hline$\leq 1$ & $45(27.9)$ \\
\hline 2 & $48(30.3)$ \\
\hline 3 or more & $65(41.8)$ \\
\hline Type of family & \\
\hline Nuclear & $57(36.0)$ \\
\hline Joint & $101(64.0)$ \\
\hline
\end{tabular}

Only $33(21 \%)$ of the women in the study had heard about cervical cancer and only $6(3.8 \%)$ of the women had heard about Pap smear. 140 (88.6\%) women were not aware of a single symptom of cervical cancer. Only 18 $(11.4 \%)$ of the women were able to state at least one symptom of cervical cancer Inter-menstrual bleeding was the commonest symptom reported followed by foul smelling discharge and $3(1.9 \%)$ of the women were able to state at least one risk factor about cervical cancer (multiple sexual partners and cigarette smoking were the mentioned risk factors) (Table 2). None of the women were able to state other risk factors like poor menstrual hygiene, early onset of sexual activity, multiparty, young age at marriage and childbirth, and long-term use of oral contraceptive pills. The main source of awareness among those who heard about cervical cancer was family and friends (21\%) followed by doctors (18.2\%). Only 1 $(0.6 \%)$ had heard about HPV vaccine and two women told that they would take HPV vaccine and allow their daughters to take it too (Table 2). Only $4(3 \%)$ of the 
women ever had Pap smear done. Two of them had done it as a part of their infertility treatment while 2 of them were advised by a doctor for irregular menstruation. The most common reason stated for poor practice of Pap smear was lack of awareness (94\%).

Table 2: Awareness about cervical cancer $(n=158)$.

\begin{tabular}{|ll|}
\hline Cervical cancer & N $(\%)$ \\
\hline Heard about cervical cancer & $33(21.0)$ \\
\hline Able to state at least 1 symptom of cervical cancer & $18(11.4)$ \\
\hline Able to state at least 1 risk factor for cervical cancer & $3(1.9)$ \\
\hline Aware that cervical cancer is curable if detected early & $2(1.3)$ \\
\hline Pap smears & $6(4.0)$ \\
\hline Heard of Pap smear & $1(0.6)$ \\
\hline Aware that women with normal Pap smear should repeat Pap smears in the future & $4(3.0)$ \\
\hline Ever had a Pap smear done & $40(25.3)$ \\
\hline Willing to undergo Pap smear if facility was available & $1(0.6)$ \\
\hline HPV vaccine & $1(0.6)$ \\
\hline Aware of a vaccine for preventing cervical cancer & $2(1.3)$ \\
\hline Heard about HPV vaccine & $2(1.3)$ \\
\hline Would take HPV vaccine if given free & \\
\hline Would allow daughters to be vaccinated against HPV & \\
\hline
\end{tabular}

Table 3: Association between socio-demographic factors and having heard of cervical cancer $(\mathbf{n}=158)$.

\begin{tabular}{|c|c|c|c|c|c|}
\hline \multirow{2}{*}{ Variable } & \multirow{2}{*}{ Category } & \multirow{2}{*}{ Total } & \multicolumn{2}{|c|}{ Heard of cervical cancer } & \multirow{2}{*}{$\begin{array}{l}\mathrm{p} \\
\text { value }\end{array}$} \\
\hline & & & Yes, 33 (21) & No, 125 (79) & \\
\hline \multirow{2}{*}{ Occupation } & Homemaker & $133(84.0)$ & $18(13.5)$ & $115(86.5)$ & \multirow{2}{*}{$0.022 \#$} \\
\hline & Gainfully employed & $25(16.0)$ & $15(60)$ & $10(40)$ & \\
\hline \multirow{3}{*}{ Marital status } & Single & $2(1.3)$ & $2(100)$ & $0(0)$ & \multirow{3}{*}{$0.039 *$} \\
\hline & Married & $145(91.8)$ & $31(21.4)$ & $114(78.6)$ & \\
\hline & Widowed/separated & $11(6.9)$ & $0(0)$ & $11(100)$ & \\
\hline \multirow{2}{*}{ Cervical cancer among family or friends } & Yes & $17(10.8)$ & $15(88.2)$ & $2(11.8)$ & \multirow{2}{*}{0.000} \\
\hline & No & $141(89.2)$ & $18(12.8)$ & $123(87.2)$ & \\
\hline
\end{tabular}

\#Chi square test *Fischer Exact test; (All the numbers in parentheses are row percentages, except in the total column, where they are column percentages).

Table 4: Association between socio-demographic variables and stating at least one symptom of cervical cancer $(\mathbf{n}=158)$.

\begin{tabular}{|c|c|c|c|c|c|}
\hline \multirow[t]{2}{*}{ Variables } & \multirow[t]{2}{*}{ Category } & \multirow[t]{2}{*}{ Total } & \multicolumn{2}{|c|}{$\begin{array}{l}\text { Able to state at least one } \\
\text { symptom of cervical cancer }\end{array}$} & \multirow{2}{*}{$\begin{array}{l}\mathrm{p} \\
\text { value }\end{array}$} \\
\hline & & & Yes, 18 (11.4) & No, $140(88.6)$ & \\
\hline \multirow{2}{*}{ Occupation } & Homemaker & $133(84.0)$ & $4(3)$ & $129(97)$ & \multirow{2}{*}{$0.000^{*}$} \\
\hline & Gainfully employed & $25(16.0)$ & $11(44)$ & $14(56)$ & \\
\hline \multirow{5}{*}{ Socio-economic class } & Upper class & $21(13.3)$ & $0(0)$ & $21(100)$ & \multirow{5}{*}{$0.019 *$} \\
\hline & Upper middle class & $51(32.3)$ & $4(8)$ & $47(92)$ & \\
\hline & Middle class & $43(27.2)$ & $11(25.6)$ & $32(74.4)$ & \\
\hline & Lower middle class & $34(21.5)$ & $3(8.8)$ & $31(91.2)$ & \\
\hline & Lower class & $9(5.7)$ & $0(0)$ & $9(100)$ & \\
\hline
\end{tabular}

*Fischer exact test; (All the numbers in parentheses are row percentages, except in the total column, where they are column percentages).

As very few study subjects were aware of cervical cancer and Pap smears, only the following outcome variables could be tested for association with socio-demographic factors: Heard of cervical cancer - $33(21 \%)$ and stating at least one symptom of cervical cancer - 18 (11.4\%). It was found that women who were gainfully employed and single women were significantly more likely to have heard about cervical cancer (Table 3). Women who had 
heard of cervical cancer were significantly more likely to report cervical cancer among family members or friends. Women who were gainfully employed and those belonging to middle class were significantly more likely to state at least one symptom of cervical cancer (Table 4). There was no significant association between these two outcome variables and other factors like age, residence, religion, parity, type of family. After multiple logistic regression analysis, women who were gainfully employed were found to be 32 times more likely to have heard about cervical cancer than those who had not, $\mathrm{OR}=32$; (8.8-111.2) (Table 5). Women who had heard of cervical cancer were 116 times more likely to report cervical cancer among family members of friends. $\mathrm{OR}=116$; (20.2-665.4).

Table 5: Multiple logistic regression $(n=158)$.

\begin{tabular}{|c|c|c|c|c|c|}
\hline \multirow{2}{*}{ Variables } & \multirow{2}{*}{ Category } & \multicolumn{3}{|c|}{ Heard about cervical cancer } & \multirow{2}{*}{$\mathrm{p}$ value } \\
\hline & & Odds ratio & $95 \%$ & ence interval & \\
\hline \multirow{2}{*}{ Occupation } & Homemaker & 1 & 1 & - & \multirow{2}{*}{0.000} \\
\hline & Gainfully employed & 31.4 & 8.8 & 111.2 & \\
\hline \multirow{2}{*}{ Cervical cancer among family/friends } & No & 1 & 1 & - & \multirow{2}{*}{0.000} \\
\hline & Yes & 115.9 & 20.2 & 665.4 & \\
\hline
\end{tabular}

\section{DISCUSSION}

Cervical cancer is one of the commonest, most deadly, yet preventable cancer. However, in the present study it was found that awareness of rural women regarding cervical cancer symptoms, risk factors and its prevention and screening was very poor. Only $21 \%$ of the women in the present study had heard about cervical cancer which was similar to a community based study done in Botswana (23\%) among women and very much in contrast to study done among women aged 14 to 58 years who were recruited from obstetric clinics, hospitals and universities in Khartoum in Sudan (87\%) and women attending a secondary care hospital in rural Andhra Pradesh $(76 \%)$, where it was found to be much higher. ${ }^{9-11}$ This could be due to the women in those studies being better educated, or having access to information regarding cervical cancer which has improved their awareness. ${ }^{9,10}$ In many parts of rural India, there exists a culture of silence around women's reproductive health and access to information about cervical cancer remains abysmal in these cultural settings. In the present study, inter menstrual bleeding was the most common symptom of cervical cancer mentioned followed by foul smelling discharge, which was similar to a study done among women attending a tertiary care hospital in Bhopal and community based study done among women in rural Uganda. ${ }^{12,13}$ As indicated from this study, major risk factors mentioned include multiple sexual partners, similarly mentioned in a community based study among women in rural areas of southern Ethiopia. ${ }^{14}$ None of the women in the present study were able to state other risk factors like HPV infection, poor menstrual hygiene, early onset of sexual activity, parity and young age at birth, multiple pregnancies, and use of oral contraceptive pills. This might be due to cultural barriers where women feel shy to discuss about gynecological problems and sexually transmitted infections, and therefore a topic often avoided even by grass root level workers in their interaction with women in the community. This was also seen in a community-based study done among women in rural Bengal. $^{15}$

Nearly all (99\%) of the women in our study, were unaware that cervical cancer is preventable. This is in much contrast to studies done in other parts of India and other countries where around $60 \%$ knew that it can be prevented. ${ }^{1-14}$ This is an alarming finding and a concern for healthcare policy makers and providers. Poor awareness regarding prevention will result in poorer utilisation of preventive services. Only few women had heard about HPV vaccine which is similar to communitybased study done in Korea and facility-based study done among women attending the primary care health centers in Bahrain (3.7\%). ${ }^{16,17}$ It is evident from our study that the awareness regarding HPV vaccine has not penetrated into rural areas.

Regarding the practice of Pap smears, almost all the women had never undergone a Pap smear test which is almost the same in comparison with other studies done in rural parts of developing countries. ${ }^{12-14}$ However, this situation is much different in developed countries with an average of $63 \%$ coverage of cancer screening. ${ }^{18}$ This is because health policy, health systems, accessibility, affordability, health seeking behaviour plays a major role in utilisation of health services. When explained about what a Pap smear is, $25.3 \%$ of women responded positively that they would like to undergo Pap smear as they thought it would benefit their health. This is in contrast to study done in Bhopal and Bengal where $80 \%$ of the women were willing to undergo Pap smear. ${ }^{12,15}$ Pap smear being a invasive procedure and cultural barriers of women being too shy to speak about gynaecological problems also play a role in this context. The other studies also included urban women and difference could 
be due largely due to the varied demography. The percentage of participants responding correctly to questions regarding the procedure, such as when to start screening, the best time to have it done, and the need for repeated pap smears was negligible.

In the present study, gainfully employed women were significantly more likely to have heard of cervical cancer and more likely to state at least one symptom of cervical cancer. This might be due to the discussion of such health-related problems with other women in the workplace. This is also supported by the finding that women who had heard of cervical cancer were significantly more likely to have had a family member or friend who suffered from cervical cancer. This point to the fact that women groups, either in the workplace or in the community could be an important resource for awareness dissemination. This finding is similar to a community-based study done in rural Congo. ${ }^{4}$

\section{CONCLUSION}

Women in our study had very poor awareness of cervical cancer and practice of Pap smears. Gainfully employed women (OR=32; 8.8-111.2) and women who reported cervical cancer among family members or friends $(\mathrm{OR}=116 ; 20.2-665.4)$. were more likely to have heard about cervical cancer. This study indicates a need to increase the awareness on cervical cancer and its prevention especially regarding Pap smears among rural women in Karnataka.

\section{ACKNOWLEDGMENTS}

Authors would like to thank Dr. Sr. Gladys, Chief of Solur Snehalaya hospital for granting us permission to conduct study. Authors also, would like to thank faculty, post-graduates and staff of Department of Community Health, St. John's Medical College, for their constant guidance and support.

Funding: No funding sources

Conflict of interest: None declared

Ethical approval: The study was approved by the Institutional Ethics Committee

\section{REFERENCES}

1. Kumar N. Women's Health and amp; Gynaecology cervical cancer; a Nightmare for Womanhood: Review of Recent Advances. Womens Heal Gynecol. 2012;2(2):30-4.

2. Shanta V, Krishnamurthi S, Gajalakshmi CK, Swaminathan R, Ravichandran K. Epidemiology of cancer of the cervix: global and national perspective. J Indian Med Assoc. 2000;98(2):49-52.

3. Geremew AB, Gelagay AA, Azale T. Comprehensive knowledge on cervical cancer, attitude towards its screening and associated factors among women aged 30-49 years in Finote Selam town, northwest Ethiopia. Reprod Health. 2018;15(1):1-12.

4. Ali-Risasi C, Mulumba P, Verdonck K, Vanden Broeck D, Praet M. Knowledge, attitude and practice about cancer of the uterine cervix among women living in Kinshasa, the Democratic Republic of Congo. BMC Womens Health. 2014;14(1):1-13.

5. Chawla PC, Chawla A, Chaudhary S. Knowledge, attitude and practice on human papillomavirus vaccination: a cross-sectional study among healthcare providers. The Indian J Med Res. 2016;144(5):741.

6. Sharma A, Kulkarni V, Bhaskaran U, Singha M, Mujtahedi S, Chatrath A, et al. Profile of cervical cancer patients attending tertiary care hospitals of Mangalore, Karnataka: a 4 year retrospective study. J Nat Sci Biol Med. 2017;8(1):125-9.

7. Safaeian M, Solomon D, Castle PE. cervical cancer prevention: cervical screening: science in evolution. Obstet Gynecol Clin North Am. 2007;34(4):739-60.

8. Rath GK, Gandhi AK. National cancer control and registration program in India. Indian J Med Paediatr Oncol. 2014;35(4):288-90.

9. Narayana G, Suchitra MJ, Sunanda G, Ramaiah JD, Kumar BP, Veerabhadrappa KV. Knowledge, attitude, and practice toward cervical cancer among women attending obstetrics and gynecology department: a cross sectional, hospital-based survey in South India. Indian J Cancer. 2017;54:481-7.

10. McFarland DM. cervical cancer and Pap smear screening in Botswana: knowledge and perceptions. Int Nurs Rev. 2003;50(3):167-75.

11. Almobarak AO, Elbadawi AA, Elmadhoun WM, Elhoweris $\mathrm{MH}$, Ahmed MH. Knowledge, attitudes and practices of sudanese women regarding the Pap smear test and cervical cancer. Asian Pacific $\mathbf{J}$ Cancer Prev. 2016;17(2):625-30.

12. Kokane A, Bansal A, Pakhare A, Kapoor N, Mehrotra R. Knowledge, attitude, and practices related to cervical cancer among adult women: A hospital-based cross-sectional study. J Nat Sci Biol Med. 2015;6(2):324.

13. Mukama T, Ndejjo R, Musabyimana A, Halage AA, Musoke D. Women's knowledge and attitudes towards cervical cancer prevention: a cross sectional study in Eastern Uganda. BMC Womens Health. 2017;17(1):1-8.

14. Aweke YH, Ayanto SY, Ersado TL. Knowledge, attitude and practice for cervical cancer prevention and control among women of childbearing age in Hossana Town, Hadiya zone, Southern Ethiopia: Community-based cross-sectional study. PLoS One. 2017;12(7):1-18.

15. Raychaudhuri S, Mandal S. Socio-demographic and behavioural risk factors for cervical cancer and knowledge, attitude and practice in rural and urban areas of North Bengal, India. Asian Pac J Cancer Prev. 2012;13(4):1093-6.

16. Tran NT, Taylor R, Choe S Il, Pyo HS, Kim OS, So HC. Knowledge, attitude and practice (KAP) 
Concerning cervical cancer and screening among rural and urban female healthcare practitioners in the Democratic People's Republic of Korea. Asian Pacific J Cancer Prev. 2011;12(11):3023-8.

17. Jassim G, Obeid A, Al Nasheet HA. Knowledge, attitudes, and practices regarding cervical cancer and screening among women visiting primary health care Centres in Bahrain. BMC Public Health. 2018;18(1):1-6.

18. Gakidou E, Nordhagen S, Obermeyer Z. Coverage of cervical cancer screening in 57 countries: low average levels and large inequalities. PLoS Med. 2008;5(6):e132.

Cite this article as: Kona C, Joseph M, Varghese J, Aksha M, Joseph A, Jose R, et al. Awareness of cervical cancer and practice of Papanicolou smears among adult women availing health services or visiting a rural maternity hospital, Ramnagara District, Karnataka, India. Int J Reprod Contracept Obstet Gynecol 2019;8:4303-8. 